\title{
E ISSN : 2580-5517 \\ PENGARUH PENGAJUAN DAN PEMECAHAN MASALAH (JUCAMA) TERHADAP KEMAMPUAN BERPIKIR KREATIF MATEMATIKA SISWA KELAS IV SEKOLAH DASAR
}

\section{THE EFFECT OF SUBMISSION AND TROUBLESHOOTING (JUCAMA) ON CREATIVE THINKING ABILITY OF MATHEMATICAL FOURTH GRADE ELEMENTARY SCHOOL LEARNERS}

\author{
Ayu Fitri ${ }^{1}$, Nur Afifah ${ }^{2}$ \\ ${ }^{1,2}$ FKIP Universitas Buana Perjuangan \\ Email : ayufitri@ubpkarawang.ac.id
}

\begin{abstract}
Abstrak
Penelitian ini bertujuan untuk mengetahui pengaruh model pengajuan dan pemecahan masalah (JUCAMA) terhadap kemampuan berpikir kreatif Matematika siswa kelas IV sekolah dasar yang dilaksanakan di Sekolah Dasar Negeri Sukamakmur 1. Penelitian ini merupakan jenis penelitian kuantitatif. Populasi yang digunakan dalam penelitian ini adalah seluruh siswa kelas IV SD Negeri Sukamakmur 1 yang berjumlah 97 siswa. Peneliti mengambil sampel 40 siswa dari jumlah populasi yang ada. Teknik pengumpulan data melalui tes soal Kelipatan Persekutuan Terkecil (KPK) dan Faktor Persekutuan Terbesar (FPB) pada soal Matematika. Teknik analisis data untuk menguji hipotesis dilakukan dengan perhitungan pearson product moment. Hasil dari uji validitas tes soal Matematika diperoleh 10 butir instrumen yang valid dari 10 butir instrumen yang diujicobakan. Hasil uji reliabilitas nilai $\mathrm{r}_{20}$ sebesar 0,939 . Hasil pengujian hipotesis, terdapat pengaruh yang signifikan penerapan model pengajuan dan pemecahan masalah (JUCAMA) terhadap kemampuan berpikir kreatif Matematika siswa kelas IV. Hal ini diperoleh probabilitas (signifikansi) 0.000 $<0.050$ menunjukkan adanya pengaruh model pengajuan dan pemecahan masalah (JUCAMA) terhadap kemampuan berpikir kreatif Matematika siswa kelas IV.
\end{abstract}

\begin{abstract}
:
This study aims to determine the effect of the model of problem submission and troubleshooting (JUCAMA) on the mathematical creative thinking ability of fourth grade learners in elementary school. This location was conducted at Sukamakmur 1 State Elementary School. This research is a type of Quantitative Research. The population who was used in this study. There were all fourth grade learners of State Elementary School Sukamakmur 1 with totalling 97 learners. Researcher took a sample of 40 learners from the existing population. Data Collection Techniques were through tests about the Smallest Guild Multiplication (KPK) and the Biggest Guild Factor (FPB) in Mathematical Questions. Data Analysis Techniques to test hypothesis were done by calculating Pearson Product Moment. The result of the validity test of mathematical questions were obtained 10 valid instruments from the 10 items tested. The reliability test resulted of the 20 value were 0/939. The result of testing the hypothesis, there was a significant effect of the application of the model of problem submission and troubleshooting (JUCAMA) to the Mathematical Creative Thinking Ability of fourth grade learners. This was obtained probability (significance) $0.000<0.050$ showed the influence of submission and troubleshooting model (JUCAMA) on Mathematical Creative Thinking Ability of fourth grade learners.
\end{abstract}

Keywords:

Thinking ability, Creative, Mathematics.

\section{PENDAHULUAN / INTRODUCTION}

Pembelajaran Matematika mempunyai beberapa tujuan. Tujuan pembelajaran Matematika sesuai Kemendikbud 2013 yaitu (1) meningkatkan kemampuan intelektual, khususnya kemampuan tinggi siswa, (2) membentuk kemampuan siswa dalam menyelesaikan suatu masalah secara sistematik, (3) memperoleh hasil belajar yang tinggi, (4) melatih siswa 
dalam mengkomunikasikan ide-ide, khususnya dalam menulis karya ilmiah, dan (5) mengembangkan karakakter siswa. Tujuan pembelajaran Matematika untuk SD/MI yaitu agar siswa mengenal angka-angka sederhana, operasi hitung sederhana, pengukuran, dan bidang.

Kemampuan intelektual diperlukan untuk mewujudkan tujuan pembelajaran Matematika, dimana kemampuan tersebut terbentuk karena adanya proses belajar dan berlatih. Kemampuan siswa dibutuhkan untuk menyelesaikan suatu masalah. Suatu masalah dalam Matematika memerlukan cara penyelesaian masalah yang disebut pemecahan masalah (problem solving). Memecahkan masalah tidaklah mudah karena harus ada kekreativitasan yang tinggi. Namun, hal tersebut dapat diatasi dengan menerapkan model pembelajaran yang dapat digunakan untuk memecahkan masalah serta memunculkan kekreativitasan melalui berpikir kreatif dalam Matematika (creative thingking of mathematics).

Model pembelajaran merupakan suatu strategi yang digunakan dalam pembelajaran guna mempermudah informasi yang disampaikan serta menjadi solusi dalam memecahkan masalah. Salah satu model pembelajaran yang berkaitan dengan pemecahan masalah adalah model pengajuan dan pemecahan masalah (JUCAMA).

Model pengajuan dan pemecahan masalah merupakan pengembangan dari model pembelajaran berbasis masalah (problem posing), dimana dalam model ini membutuhkan lebih banyak keterlibatan siswa, siswa dituntut untuk dapat membuat pertanyaan sendiri berkaitan apa yang telah didapatkannya, dalam membuat pertanyaan tersebut, siswa nantinya memerlukan proses berpikir kreatif. Berpikir kreatif siswa terjadi apabila siswa dapat memunculkan ide-ide baru dan mampu mengkomunikasikan ide-ide tersebut sehingga memperoleh hasil belajar yang tinggi. Mengkomunikasikan ide-ide dapat dilakukan melalui kesiapan mental serta kecakapan siswa sacara aktif.

Namun, pada kenyataannya masih banyak siswa yang belum memiliki kemampuan berpikir kreatif dan belum mampu mengerjakan soal secara sistematis, sehingga kurang cakap dalam memecahkan masalah, masih ada anak yang belum mampu berhitung secara lancar sehingga menghambat proses mengerjakan soal Matematika dalam operasi hitung, masih banyak siswa yang belum lancar perkalian sehingga kesulitan dam mengerjakan soal yang terdapat materi perkaliannya (seperti faktosisasi bilangan, FPB, KPK) seperti masalah yang terjadi di SD Negeri Sukamakmur 1, sesuai dengan informasi yang diperoleh dari observasi pada tanggal 3 Agustus 2018 di SD Negeri Sukamakmur 1 Desa Gempol Girang Karawang, dimana masih ada siswa yang belum mampu memecahkan masalah yang berhubungan dengan Matematika khususya berhubungan dengan operasi hitung, perkalian dan faktorisasi, mereka masih kesulitan dalam mengerjakan soal Matematika yang dalam menyelesaikannya memerlukan pemecahan masalah berupa menganalisis soal menentukan apa yang ditanyakan serta menyimpulkan jawaban, sebagian siswa tersebut tidak menyukai Matematika karena dianggap sulit, hal tersebut dikarenakan siswa kurang mengembangkan kemampuan berpikir kreatifnya.

\section{METODE / METHOD}

Penelitian ini menggunakan pendekatan kuantitatif dengan jenis penelitian eksperimen semu (quasy eksperimen). Desain yang digunakan dalam penelitian ini yaitu nonequivalent comparison-group design oleh Johnson and Christensen (dalam Sugiono 2013:77) Rancangan tersebut disajikan pada tabel berikut :

\section{Tabel 1}

Desain penelitian 


\begin{tabular}{|l|l|l|l|}
\hline Kelas & Pretest & Perlakuan & Posttest \\
\hline $\mathrm{K} 1$ & $\mathrm{O}_{1}$ & $\mathrm{X}_{1}$ & $\mathrm{O}_{3}$ \\
\hline $\mathrm{K} 2$ & $\mathrm{O}_{2}$ & $\mathrm{X}_{2}$ & $\mathrm{O}_{4}$ \\
\hline
\end{tabular}

Keterangan :

K1 : Kelas Kontrol

K2 : Kelas Eksperimen

$\mathrm{O}_{1}$ : Pre-test Kelas Kontrol

$\mathrm{O}_{3}$ : $\quad$ Post-test Kelas Kontrol

$\mathrm{O}_{2}$ : $\quad$ Pre-test Kelas Eksperimen

$\mathrm{O}_{4}$ : $\quad$ Post-test Kelas Eksperimen

$\mathrm{X}_{1}$ : Perlakuan pada kelas eksperimen 1 menggunakan metode pembelajaran konvensional.

$\mathrm{X}_{2}$ : Perlakuan pada kelas eksperimen 2 menggunakan model pengajuan dan pemecahan masalah (JUCAMA).

Tes awal (pre-test) diadakan pada kedua kelas, yaitu kelas kontrol (kelas eksperimen 1) dan kelas eksperimen (kelas eksperimen 2). Setelah itu dilakukan uji perbedaan untuk mendapatkan kondisi awal yang sama. Pada akhir perlakuan dilihat perbedaan pencapaian atau perolehan pre-test dan post-test kelompok eksperimen (1-3 dan 2-4). Hasil test kemampuan berpikir kreatif dan skala pemecahana masalah pada masing-masing kelas diuji perbedaannya. Apabila antara tes dan skala kedua kelas terdapat perbedaan, maka akan diketahui efektif atau tidaknya dari perlakuan yang diberikan. Tahap-tahap yang dilakukan dalam penelitian ini sebagai berikut :

1. Menyampaikan tujuan dan mempersiapkan siswa.

2. Mengorientasikan siswa pada masalah melaui pemecahan atau pengajuan masalah dan mengorganisasikan siswa untuk belajar.

3. Membimbing penyelesaian secara individual maupun kelompok.

4. Menyajikan hasil penyelesaian pemecahan dan pengajuan masalah.

5. Memeriksa pemahaman dan memberikan umpan balik sebagai evaluasi.

\section{Populasi penelitian}

Populasi pada penelitian ini adalah seluruh siswa kelas IV SD Negeri Sukamakmur 1 Kabupaten Karawang.

\section{Sampel Penelitian}

Sampel penelitian ini adalah siswa kelas IV SD Negeri Sukamakmur yang selanjutnya dipilih secara acak untuk menentukan kelas mana yang akan diberi perlakuan dengan menerapkan model pengajuan dan pemecahan masalah (JUCAMA) dan yang diberi perlakuan dengan model pembelajaran konvensional.

\section{Teknik Pengumpulan Data}

Teknik pengumpulan data merupakan teknik yang berkaitan dengan cara atau metode yang digunakan dalam proses pengumpulan data, teknik pengumpulan data disesuaikan dengan jenis data yang dibutuhkan. Adapun teknik pengumpu;an data yang digunakan dalam penelitian ini adalah observasi dan tes.

\section{Teknik Analisis Data}




\section{Statistik Deskriptif}

Teknik anaisis data yang digunakan berupa analisis data deskriptif. Bentuk penyajian analisis deskriptif yaitu data. Data yang diperoleh melalui pretest dan posttest berupa soal kemampuan menyelesaikan soal cerita Matematika.

Pada statistik deskriptif menggunakan ukuran nilai tengah dan ukuran deviasi. Ukuran nilai tengah terdiri dari rata-rata (mean), median, dan modus. ukuran deviasi terdiri dari varians, simpangan baku, koefisien variasi, dan nilai jarak (range).

\section{Uji Inferensial}

a. Uji Normalitas

Uji normalitas data dilakukan untuk mengetahui sampel yang diteliti berdistribusi normal atau tidak. Pada penelitian ini uji normalitas yang dilakukan menggunakan Program SPSS Versi 25.00.

Langkah-langkah melakukan uji normalitas dengan Program SPSS versi 25.00:

1. Persiapkan data yang ingin diuji dalam file doc, excel, atau yang lainnya untuk mempermudah tahapanya.setelah itu buka program SPSS pada komputer, lalu klik variabel view, dibagian pojok kiri bawah. Selanjutnya, pada bagian "Name" tulis Hasil kemudian Kelas, pada "Desimals" ubah semua menjadi angka 0, untuk bagian "Label" tuliskan kemampuan berpikir kreatif kemudian Kelas. Abaikan yang lainnya biarkan tetap default.

2. Klik data View dan masukkan data yang sudah dipersiapkan tadi ke dalam program SPSS sesuai nama variabel.

3. Munculkan nilai unstandardized residul (RES_1), selanjutnya diuju normalitasnya dengan cara pilih menu Analyze kemudian klik Regression lalu pilih Linear.

4. Muncul kotak dialog dengan nama Linear Regression, selanjutnya masukan variabel Y ke Dependent dan Variabel X ke kotak Independent(s), kemudian klik save.

5. Maka akan muncul kembali kotak dialog dengan nama "Linear Regression: Save" pada bagian Residual centang pada Unstadardized (abaikan kolom dan pilihan yang lain), selanjutnya klik continue lalu klik ok.

6. Perhatikan pada tampilan Data View, maka akan muncul Variabel baru dengan nama RES_1.

7. Lakukan uji normalitas kolmogorov-smirnov, pilih menu Analyze lalu pilih Nonparametric Tests, klik Legacy Dialogs kemudian pilih menu 1-Sample K-S

8. Muncul kotak dialog lagi dengan nama "One Sample Kolmogorov Smirnov Test", selanjutnya masukkan variabel Unstandardized Residuals ke kotak Test Variabel List: pada "Test Distribution" centang pilihan normal.

9. Klik ok untuk mengakhiri perintah.

\section{b. Uji Homogenitas}

Uji homogenitas dimaksudkan untuk mengetahui apakah subjek penelitian berasal dari populasi homogen atau tidak. Pada penelitian ini, kelompok yang dibandingkan adalah kelompok eksperimen dan kelompok kontrol. Dari kedua kelompok tersebut dinyatakan homogen apabila variannya relatif sama. Perhitungan uji homogenitas dengan menggunakan statistik (Uji T).

Ketentuan taraf signifikansi 0,05 dengan kriteria :

1) Data variansi yang sama (homogen) : jika nilai probabilitas lebih besar dari 0,05

2) Data variansi tidak sama (tidak homogen) : jika nilai probabilitas lebh kecil dari 0,05

3. Hipotesis Statistik

Uji hipotesis dilakukan untuk mengetahui pengaruh kemampuan berpikir kreatif Matematika sebelum dan sesudah diberi perlakuan model pengajuan dan pemecahan masalah (JUCAMA). Uji hipotesis dalam penelitian ini menggunakan uji t dengan Program SPSS Versi 25.00 . 
Kriteria pengujiannya adalah jika signifkansi (probabilitas) yang dihasilkan lebih kecil dari 0,05 maka $\mathrm{H}_{0}$ ditolak.

$\mathrm{H}_{\mathrm{o}} \quad=\mu_{1}>\mu_{2} \rightarrow$ diterima

$\mathrm{H}_{\mathrm{a}} \quad=\mu_{1}<\mu_{2} \rightarrow$ ditolak

Jika $t_{\text {hitung }}>\mathrm{t}_{\text {tabel}}$, maka $\mathrm{H}_{\mathrm{o}}$ ditolak dan $\mathrm{H}_{\mathrm{a}}$ diterima

Jika $t_{\text {hitung }}<\mathrm{t}_{\text {tabel}}$, maka $\mathrm{H}_{\mathrm{o}}$ diterima dan $\mathrm{H}_{\mathrm{a}}$ ditolak

$\mathrm{H}_{\mathrm{o}} \quad=\mu_{1}=\mu_{2} \rightarrow$ diterima.

$\mathrm{H}_{\mathrm{a}} \quad=\mu_{1} \neq \mu_{2} \rightarrow$ ditolak

Jika $\mathrm{t}_{\text {hitung }}=\mathrm{t}_{\text {tabel }}$, maka $\mathrm{H}_{\mathrm{o}}$ ditolak dan $\mathrm{H}_{\mathrm{a}}$ diterima

Jika $t_{\text {hitung }} \neq \mathrm{t}_{\text {tabel}}$, maka $\mathrm{H}_{\mathrm{o}}$ diterima dan $\mathrm{H}_{\mathrm{a}}$ ditolak

\section{HASIL DAN PEMBAHASAN / RESULT AND DISCUSSION}

1. Deskripsi Data Pre-test Kelas Eksperimen dan Kelas Kontrol

Tabel 2 Rangkuman data Statistik Nilai Pretest Kemampuan Berpikir Kreatif Matematika Kelas Eksperimen dan Kelas Kontrol

\begin{tabular}{|c|c|c|c|c|c|c|}
\hline No & Kelas & $\mathrm{N}$ & $\begin{array}{c}\text { Nilai } \\
\text { maksimal }\end{array}$ & $\begin{array}{c}\text { Nilai } \\
\text { minimal }\end{array}$ & Mean & $\begin{array}{c}\text { Standar } \\
\text { deviasi }\end{array}$ \\
\hline 1 & Eksperimen & 20 & 84 & 22 & 57.00 & 20.267 \\
\hline 2 & Kontrol & 20 & 74 & 38 & 61.95 & 10.118 \\
\hline
\end{tabular}

2. Deskripsi Data Post-test Kelas Eksperimen dan Kelas Kontrol

Tabel 3 Rangkuman Data Statistik Nilai Posttest Kemampuan Berpikir Kreatif Matematika Kelas Eksperimen dan Kelas Kontrol

\begin{tabular}{|c|c|c|c|c|c|r|}
\hline No & Kelas & $\mathrm{N}$ & $\begin{array}{c}\text { Nilai } \\
\text { maksimal }\end{array}$ & $\begin{array}{c}\text { Nilai } \\
\text { minimal }\end{array}$ & Mean & $\begin{array}{c}\text { Standar } \\
\text { deviasi }\end{array}$ \\
\hline 1 & Eksperimen & 20 & 100 & 60 & 86.85 & 10.414 \\
\hline 2 & Kontrol & 20 & 86 & 56 & 72.40 & 6.992 \\
\hline
\end{tabular}

\section{ANALISIS INFERENSIAL}

\section{Uji Normalitas Pretest dan Posttest}

Pada uji normalitas untuk mengetahui data yang diperoleh dari hasil nilai Pretest dan posttest berdistribusi normal atau tidak. Peneliti menggunakan Program SPSS versi 25.00 dalam menghitung uji normalitas menggunakan kolmogorov-smirnov dan saphiro-Wilk yang menunjukkan normal atau tidaknya data yang dihasilkan. Sebuah syarat berdistribusi normal apabila signifikan yang diperoleh dari hasil perhitungan lebih besar dari tingkat alpha 5\% (signifikansi $>0,05$ ).

Hasil uji normalitas data pretest-posttest kemampuan berpikir kreatif Matematika kedua sampel penelitian dapat disajikan dalam tabel sebagai berikut: 
ISSN : 2541-6995

E ISSN : 2580-5517

Tabel 4 Hasil Uji Normalitas Pretest dan Posttest Kelas Eksperimen dan Kelas Kontrol

Tests of Normality

\begin{tabular}{|c|c|c|c|c|c|c|c|}
\hline & \multirow[b]{2}{*}{ Kelas } & \multicolumn{3}{|c|}{ Kolmogorov-Smirnov ${ }^{a}$} & \multicolumn{3}{|c|}{ Shapiro-Wilk } \\
\hline & & Statistic & df & Sig. & Statistic & df & Sig. \\
\hline \multirow[t]{4}{*}{$\begin{array}{l}\text { Kemampuan berpikir } \\
\text { kreatif siswa }\end{array}$} & $\begin{array}{l}\text { Pre-Test Eksperimen } \\
\text { (JUCAMA) }\end{array}$ & .159 & 20 & $.200^{\star}$ & .917 & 20 & .085 \\
\hline & $\begin{array}{l}\text { Post-test Eksperimen } \\
\text { (JUCAMA) }\end{array}$ & .167 & 20 & .143 & .925 & 20 & .123 \\
\hline & $\begin{array}{l}\text { Pre-Test Kontrol } \\
\text { (Konvensional) }\end{array}$ & .187 & 20 & .065 & .905 & 20 & .050 \\
\hline & $\begin{array}{l}\text { Post-Test Kontrol } \\
\text { (Konvensional) }\end{array}$ & .184 & 20 & .074 & .943 & 20 & .268 \\
\hline
\end{tabular}

Hal ini membuktikan bahwa kedua nilai baik dari kelas eksperimen maupun kontrol lebih besar dari bilai alpha 0.05 . kerana nilai signifikan kedua kelas lebih besar dari nilai alpha $\alpha 0.05$ ( 0.200 dan $0.065>=\alpha 0.05)$, maka data kedua kelas berdistribusi normal.

\section{Uji Homogenitas Pretest dan Posttest}

Setelah melakukan uji normalitas dari dua kelas yang sudah dinyatakan berdistribusi normal, selanjutnya mencari nilai homogenitas varians pretest dan posttest dari kedua kelas tersebut. Perhitungan uji Homogenitas dengan menggunakan SPSS versi 25.00. adapun kriteria pengujian homogenitas sebagai berikut :

a. Jika probabilitas (signifikansi) $>=0.050$, maka Ho diterima, artinya varians dinyatakan Homogen.

b. Jika probabilitas (signifikansi) $<0.50$, maka Ho Ditolak, artinya varians dinyatakan Heterogen.

Tabel 5 Hasil Uji Homogenitas Pretest dan Posttest Kelas Eksperimen dan Kelas Kontrol

Test of Homogeneity of Variance

\begin{tabular}{ll|r|r|r|r} 
& \multicolumn{2}{c}{$\begin{array}{c}\text { Levene } \\
\text { Statistic }\end{array}$} & df1 & \multicolumn{1}{c|}{ df2 } & \multicolumn{1}{c}{ Sig. } \\
\hline $\begin{array}{l}\text { Kemampuan berpikir } \\
\text { kreatif siswa }\end{array}$ & Based on Mean & 2.589 & 1 & 38 & .116 \\
\cline { 2 - 7 } & Based on Median & 2.764 & 1 & 38 & .105 \\
\cline { 2 - 7 } & $\begin{array}{l}\text { Based on Median and } \\
\text { with adjusted df }\end{array}$ & 2.764 & 1 & 35.106 & .105 \\
\cline { 2 - 7 } & Based on trimmed mean & 2.627 & 1 & 38 & .113 \\
\hline
\end{tabular}

Berdasarkan tabel Tabel 4.6 Hasil Uji Homogenitas Pretest dan Posttest Kelas Eksperimen dan Kelas Kontrol menunjukkan bahwa nilai probabilitas (signifikansi) adalah $0.116>\alpha 0.050$ untuk levene Stastistic 2.589, 0.105> $>0.050$ untuk levene Stastistic 2.764, dan $0.113>\alpha 0.050$, maka Ho diterima. Hal ini membuktikan bahwa kedua sampel dari kelas Eksperimen dan Kelas Kontrol berasal dari kelas yang homogen.

\section{PENGUJIAN HIPOTESIS}

Tabel 6 Hasil Uji T-Test kelas Eksperimen dan Kelas Kontrol 
Ayu Fitri, Nur Afifah

Vol 4 No 1

ISSN : 2541-6995

E ISSN : 2580-5517

\begin{tabular}{|c|c|c|c|c|c|c|c|c|c|}
\hline \multicolumn{10}{|c|}{ Paired Samples Test } \\
\hline & & \multicolumn{5}{|c|}{ Parred Differences } & \multirow[b]{3}{*}{ t } & \multirow[b]{3}{*}{ of } & \multirow[b]{3}{*}{ Sig. [2tailed) } \\
\hline & & \multirow[b]{2}{*}{ Мean } & \multirow[b]{2}{*}{ Std Deviation } & \multirow{2}{*}{$\begin{array}{l}\text { Str. Enor } \\
\text { Mean }\end{array}$} & \multicolumn{2}{|c|}{$\begin{array}{l}\text { 95\% Confidence intenal of the } \\
\text { Dfferense }\end{array}$} & & & \\
\hline & & & & & Lower: & Upper & & & \\
\hline Part 1 & $\begin{array}{l}\text { Pre-Test Eksperimen- } \\
\text { PostTest Elsperimen }\end{array}$ & -29.850 & 17.933 & 4.010 & -38.243 & -21.457 & -7.444 & 19 & .000 \\
\hline $\operatorname{Par} 2$ & $\begin{array}{l}\text { Pre-TestKontrol-Post- } \\
\text { Test Kontrol }\end{array}$ & -10.450 & 7273 & 1.626 & -13.854 & -7.046 & -6.426 & 19 & .000 \\
\hline
\end{tabular}

Berdasarkan tabel Tabel 4.7 Hasil Uji T-Test kelas Eksperimen dan Kelas Kontrol Paired Samples Test (uji hipotesis) menunjukkan bahwa nilai probabilitas (signifikansi) adalah 0.000. karena signifikansi $0.000<\alpha 0.050$, maka Ho ditolak. Hal ini membuktikan bahwa terdapat pengaruh penggunaan model pengajuan dan pemecahan masalah (JUCAMA) terhadap kemampuan berpikir kreatif Matematika siswa kelas IV sekolah dasar.

\section{PEMBAHASAN}

Pada saat pembelajaran berlangsung sistem pembelajaran yang digunakan dengan menggunkan model pengajuan dan pemecahan masalah (JUCAMA) dimana pada pemebelajaran model ini siswa diharuskan mampu memecahakan masalah yang ditemukannya sendiri. Pembelajaran model ini bersifat student-centered, guru hanya sebagai fasilitator dan pengawas.

Garis besar kondisi pelaksanaan proses pembelajaran dengan menggunakan model pengajuan dan pemecahan masalah (JUCAMA) diawali dengan guru memberikan suatu masalah berkaitan dengan masalah Matematika yaitu KPK dan FPB yang kemudian anak tersebut akan memecahkan soal tersebut sesuai dengan pengetahuan mereka. Guru menjadi fasilitator meliputi menjawab jika ada siswa yang ingin bertanya dan lainnya. Tahap awal pembelajaran pada kelas eksperimen sama dengan kelas kontrol yaitu dengan melakukan pretest. Setelah hasil dari pre-test didapatkan tahap selanjutnya adalah memberikan pembelajaran dengan model pengajuan dan pemecahan masalah (JUCAMA) dimana dalam perlakuan ini anak diberi tugas untuk membuat soal sendiri dan mengerjakannnya sendiri bertujuan agar anak lebih paham dengan materi yang disamapaikan, penelitian ini dilakukan 2 kali pembelajaran( 2x 60 menit) selanjutnya dilakukan post-test.

Pelaksanaan pembelajaran pada kelas kontrol menggunakan pembelajaran konvensional, yaitu dengan metode ceramah dan tanya jawab. Pelaksanaan pembelajaran dalam kelas ini dilakukan 2 kali pertemuan (2x60menit) dan satu kali pertemuan untuk post-test.

Berdasarkan penelitian yang peneliti sudah lakukan dengan nilai rata-rata pretest kelas eksperimen 57.00 dan kelas kontrol sebesar 61.95. setelah diberi perlakuan dan dilaksanakan posttest bahwa hasil akhir kelas eksperimen 86.85 lebih tinggi dibandingkan nilai rata-rata kelas kontrol 72.40. dengan melihat nilai rata-rata pretest dan posttest, pada hasil penelitian tersebut menunjukkan danya peningkatan akhir kemampuan berpikir kreatif Matematika siswa dengan menggunakan model pembelajaran pengajuan dan pemecahan masalah (JUCAMA). Penelitian ini membuktikan bahwa adanya pengaruh pada kemampuan berpikir kreatif Matematika siswa dengan menggunakan model pembelajaran pengajuan dan pemecahan masalah (JUCAMA). Sehingga dalam pelaksanaan pemebelajaran model pengajuan dan pemecahan masalah (JUCAMA) dapat dijadikan acuan oleh para guru dalam menerapkan model pembelajaran khususnya pelajaran Matematika.

\section{SIMPULAN / CONCLUSION}


Ayu Fitri, Nur Afifah

Vol 4 No 1

ISSN : 2541-6995

E ISSN : 2580-5517

Berdasarkan hasil penelitian dan analisis data, maka dapat disimpulkan bahwa penggunaan model pengajuan dan pemecahan masalah (JUCAMA) berpengaruh terhadap kemampuan berpikir kreatif Matematika siswa kelas IV SD Negeri Sukamakmur 1. Berdasarkan hasil posttest diperoleh bahwa rata-rata kemampuan berpikir kreatif Matematika siswa menggunakan model pembelajaran pengajuan dan pemecahan masalah (JUCAMA) pada kelas eksperimen lebih tinggi dibandingkan dengan rata-rata kemampuan berpikir kreatif Matematika siswa yang mendapatkan pembelajaran denagn model pembelajaran konvensional pada kelas kontrol. Rata-rata nilai pretest yang diperoleh kelas eksperimen 57.00. Rata-rata nilai pretest kelas kontrol 61.95. Setelah diberi perlakuan pada kedua kelas, maka diperoleh rata-rata posttest kelas eksperimen sebesar 86.85 dan nilai rata-rata posttest kelas kontrol 72.40. Jumlah peningkatan nilai rata-rata kelas eksperimen lebih tinggi dari jumlah rata-rata kelas kontrol. Perhitungan dengan menggunakan Uji-T yakni Uji Paired Samples T test dan diperoleh pada taraf signifikansi 0.050 menunjukkan nilai probabilitas (signifikansi) adalah 0.000 , karena nilai signifikansi kurang dari $\alpha 0.050$, maka Ho ditolak. Hal ini membuktikan bahwa penggunaan model pembelajaran pengajuan dan pemecahan masalah (JUCAMA) berpengaruh terhadap kemampuan berpikir kreatif siswa kelas IV SD Negeri Sukamakmur 1.

\section{SARAN}

Agar siswa dapat meningkatkan kemampuan berpikir kreatif Matematika, maka peneliti memberikan saran sebagai berikut ;

1. Guru hendaknya menggunakan model pembelajaran pengajuan dan pemecahan masalah dalam proses pemebelajaran agar dapat meningkatkan pola pikir kreatif Matematika.

2. Model pembelajaran yang berbeda dari biasanya sangat diperlukan agar tidak terjadi kejenuhan dan monoton dalam berpikir.

3. Bagi peneliti dapat dijadikan sebagai ilmu pengetahuan dan dapat untuk meningkatkan lagi kemampuan berpikir kreatif Matematika pada siswa kelas IV sekolah dasar. Selain itu perlu aadanya penelitian yang lebih lanjut untuk mengetahui kemampuan berpikir kreatif Matematika dengan model pengajuan dan pemecahan masalah (JUCAMA) kepada siswa lain yang belum pernah diberi model pembelajaran ini.

4. Bagi peneliti selanjutnya model pengajuan dan pemecahan masalah (JUCAMA) ini dapat diterapkan maupun diuji kembali untuk membuktikan kebenaran dari pengaruh positif penggunaan model pengajuan dan pemecahan masalah sesuai dengan penelitian ini.

\section{DAFTAR RUJUKAN / REFERENCES}

Arifin, Zaenal. (2015). Metode Penulisan Ilmiah.cetakan 5. Tangerang: Pustaka Mandiri.

Conny, R Semiawan. (2009). Kreativitas dan Keberbakatan. Jakarta: PT Indeks

Karim, Normaya. (2015). Kemampuan Berpikir Kritis Siswa dalam Pembelajaran Matematika dengan Menggunakan Model JUCAMA disekolah Menengah Pertama. Jurnal Pendidikan Matematika. Volume 3 Nomer 1

Kemendikbud. (2013). Kerangka Dasar dan Struktur Kurikulum 2013. Jakarta: Kemendikbud. 
Ayu Fitri, Nur Afifah

Vol 4 No 1

ISSN : 2541-6995

E ISSN : $2580-5517$

Kurniason. Hugo Theo (2016). Pengaruh model Matematika berbasis pengajuan dan pemecahan masalah terhadap kemampuan berpikir kreatif. Volume 6 Nomer 10

Mann,E.L. (2005). Mathematical Creativity and School Mathematics: Idicators of Mathematical Creativity in Middle Scool

Students. California: University of Southern.

Munandar,S.C.U. (1999). Kreativitas dan Keberbakatan.Strategi Mewujudkan Potensi Kreatif dan Bakat. Jakarta: PT Gramedia Pustaka Utama

Nursito. (1999). Kiat Menggali Kreativitas. Yogyakarta: Mitra Gama Widya

Pehkonen, E. (1997). The State of Art in Mathematical Creativity. http://www.fiz.karlsruhe.de/fiz/publications/zdm.ZDM

Riduwan. (2

Riduwan. (2010). Skala Pengukuran Variabel-Variabel Penelitian. Bandung: Alfabeta

Rohmatin,D.V. (2014). Pengaruh model pembelajaran pengajuan dan pemecahan masalah untuk meningkatkan kemampuan berfikir kritis siswa. Jurnal Gramatika Vol 5 Nomor 1

Rusman. (2018). Model-model Pembelajaran, cetakan ke-3. Depok: PT Raja Grafindo Persada Statistik dengan SPSS 25. ISBN: Elex Media Komputindo

Sadulloh. (2017). Pedagogik Ilmu Mendidik. Bandung : Alfabeta

Siswono, Tatag Yuli Eko . (2018). Pembelajaran Matematika Berbasis Pengajuan dan Pemecahan Masalah. Bandung : PT Remaja Rosdakarya

Siregar, Sofyan. (2013). Metode Penelitian Kuantitatif . Jakarta: PT Fajar Interpratama Mandiri

Sugiono. (2013). Metode Peneitian Kuantitatif, Kualitatif Dan R\&D. Bandung: Alfabeta

Suharsimi,Arikunto. (2015). Dasar-dasar Evaluasi Pendidikan,cetakan ke 5. Jakarta: PT Bumi Aksara

Wardono, W. (2018). Analisis Kemampuan Literasi Matematika Model Pembelajaran JUCAMA Berpendapatan PMRI dengan Google Form sebagai Self Assessment. Prisma: Prosiding Seminar Nasional Matematika. Volume 1 